\title{
Neonatal Spontaneous Intestinal Perforation, AE
}

National Cancer Institute

\section{Source}

National Cancer Institute. Neonatal Spontaneous Intestinal Perforation, AE. NCI

Thesaurus. Code C154924.

An adverse event in a newborn characterized by a perforation in the gastrointestinal tract of a newborn with no demonstrable cause. 